\title{
INTERAÇÃO NO AMBIENTE VIRTUAL DE APRENDIZAGEM NO SEMIPRESENCIAL: UM ESTUDO SOBRE A OPERACIONALIZAÇÃO DA RESOLUÇÃO 1134/2016
}

\author{
CURITIBA/PR JUNHO/2018
Nathalia Savione Machado－ UNINTER/UFPR - nathcipead@gmail.com
João Mattar - UNINTER/PUC-SP - joaomattar@gmail.com
Dinamara Pereira Machado - UNINTER - dinamara.m@uninter.com \\ Tipo: Investigação Científica (IC) \\ Natureza: Descrição de Projeto em Andamento \\ Categoria: Métodos e Tecnologias \\ Setor Educacional: EDUCAÇÃO SUPERIOR
}

\begin{abstract}
RESUMO
A resolução no 1134/2016 permite que os cursos de graduação ofertem até $20 \%$ da sua carga horária utilizando-se da modalidade a distância. Para tanto, utilizam-se de ambientes virtuais de aprendizagem na perspectiva de propiciar a comunicação e a interação entre os atores do processo educacional. $O$ objetivo deste artigo é analisar a organização e o uso de um Ambiente Virtual de Aprendizagem (AVA) em dois cursos de graduação semipresenciais, de duas instituições de ensino superior, que utilizam a modalidade a distância em até $20 \%$ dos cursos. O estudo teve o caráter exploratório desenvolvido a partir da abordagem qualitativa, compartilhando análise documental e coleta de dados por meio de observação no AVA. Diante disso, constatou-se que o ambiente virtual de aprendizagem é utilizado em todas as disciplinas de ambos os cursos, tendo como principal objetivo a disponibilização de materiais audiovisuais e a realização de avaliações. Mesmo havendo a presença docente no AVA e atividades que utilizem o recurso fórum, a interação é tímida. Conclui-se que os fatores que estimulam a interação precisam ser investigados com mais atenção.
\end{abstract}

Palavras-chave: Semipresencial. Ensino Superior. Ambiente Virtual de Aprendizagem. Interação. 


\section{INTRODUÇÃO}

Este artigo tem como objetivo analisar a organização e o uso de ambientes virtuais de aprendizagem em dois cursos de graduação semipresenciais, de duas instituições de ensino superior, que utilizam a modalidade a distância em até $20 \%$ dos cursos. $O$ problema norteador visa compreender se o uso do ambiente virtual de aprendizagem promove a interação entre os discentes, e entre docentes e discentes, potencializando 0 ensino e a aprendizagem.

O artigo está organizado em seis seções. O referencial teórico discutirá a integração das tecnologias digitais de informação e comunicação na educação e a interação e interatividade no Ambiente Virtual de Aprendizagem (AVA). Na sequência descrevem-se a metodologia e os resultados e são realizadas discussões.

\section{REFERENCIAL TEÓRICO}

Os estudos de Moran (2015), Kenski (2012) e Masetto (2012), dentre outros pesquisadores, demonstram que as instituições de ensino superior têm desenvolvido novas formas de ensinar e aprender, incorporando diferentes metodologias de ensino e integrando as tecnologias digitais. Os trabalhos desenvolvidos por Bacich, Tanzi Neto e Trevisani (2015), Horn e Staker (2015), Moran (2015) e Tori (2017) têm discutido a incorporação das tecnologias digitais no ambiente presencial por meio do ensino híbrido e da otimização do ambiente online e do uso integrado dessas duas modalidades. Nesse sentido, Kenski (2012, p. 89) aponta a necessidade de se organizar novas experiências educativas em que "as TDIC possam ser usadas em processos cooperativos de aprendizagem, em que se valorizem o diálogo e a participação permanente de todos os envolvidos". Tori (2017, p. 33) corrobora, afirmando que a educação presencial "pode e deve incorporar aos avanços metodológicos, tecnologias, ferramentas e conteúdos desenvolvidos para o ensino online. Tentar separar uma coisa de outra é que não faz mais sentido." Kenski (2012) complementa afirmando que, da mesma forma, os discentes não querem mais ficar passivos diante das tecnologias sendo simples usuários: querem participar. Ensinar utilizando as tecnologias digitais e o ensino online é desafiador e exige organização e planejamento. As tecnologias, nessa perspectiva, tornam-se facilitadoras e potencializadoras do ensino, abrindo as portas para novas possibilidades de aprendizagem. $\mathrm{O}$ uso das tecnologias aliadas à educação, em uma abordagem de diálogo e colaboração, é descrito no relatório do New Media Consortium (2016), afirmando que as instituições que adotam modelos de aprendizagem híbrida - online/presencial - têm o potencial para alavancar as habilidades que os estudantes já desenvolveram, independente da universidade. Assim, espera-se que o 
discente seja capaz de "interagir e participar socialmente, integrar-se em novas comunidades e criar novos significados para a educação" (KENSKI, 2012, p. 67).

As palavras interação e interatividade são de uso frequente na educação a distância, e muitos pesquisadores buscam conceituar e diferenciar. Moore (1989) define três tipos de interação: aluno/professor, aluno/aluno e aluno/conteúdo. Mattar (2014, p. 136) aponta que outros tipos foram adicionados ao conceito proposto por Moore:

\footnotetext{
Hillman, Willis e Gunawardena (1994) adicionam a interação aluno/interface. Soo e Bonk (1998) acrescentam a interação do aluno com ele próprio (learner-self). Sutton (2001) introduz a ideia da interação vicária. Anderson (2003a, 2003b) amplia a perspectiva de Moore, incluindo mais três tipos de interação: professor/professor, professor/conteúdo e conteúdo/conteúdo.
}

Para Belloni (2003, p. 58), a interação se define como "a ação recíproca entre dois ou mais atores onde ocorre intersubjetividade, isto é, encontro de dois sujeitos". Para a autora, esse encontro pode ocorrer em tempo real (síncrono) ou em tempos diferentes (assíncrono), ou ainda, em Lakatos (1999, p. 87):

interação social é a ação social, mutuamente orientada, de dois ou mais indivíduos em contato. Distingue-se da mera interestimulação em virtude de envolver significados e expectativas em relação às ações de outras pessoas. Podemos dizer que a interação é a reciprocidade de ações sociais.

É importante evidenciar que os meios tecnológicos são apenas meios, caminhos que são utilizados para que aconteça a comunicação entre professor e aluno, e que a interação decorre do encontro de pessoas que estabelecem relações e discutem posições, englobando ideias a partir de determinado foco.

A resolução n 1134/2016 (BRASIL, 2016) permite que os cursos de graduação ofertem até $20 \%$ da sua carga horária utilizando-se da modalidade a distância. Para isso, os cursos se utilizam de diferentes tecnologias de informação e comunicação, dentre elas os Ambientes Virtuais de Aprendizagem - AVA. Segundo Almeida (2003, p. 331), os Ambientes Virtuais de Aprendizagem são:

sistemas computacionais disponíveis na internet, destinados ao suporte de atividades mediadas pelas tecnologias de informação e comunicação. Permitem integrar múltiplas mídias, linguagens e recursos, apresentar informações de maneira organizada, desenvolver interações entre pessoas e objetos de conhecimento, elaborar e socializar produções tendo em vista atingir determinados objetivos.

$\mathrm{Na}$ esfera educacional, existem vários ambientes virtuais de aprendizagem, que são plataformas web, com características distintas, que são utilizados de diferentes formas, desde repositórios de materiais, perpassando por mecanismos de interação (chat, fórum 
e mural), até vinculação de atividades síncronas e assíncronas.

Para que a interação se estabeleça, uma ferramenta comumente utilizada é o fórum, uma atividade de discussão com diversos tipos de estruturas, que permite diálogos assíncronos sobre determinado tema. Suas mensagens podem apresentar diferentes formatos e permitem também anexar documentos. Os fóruns podem ser organizados de diferentes formas, de acordo com seu objetivo pedagógico.

\section{METODOLOGIA}

O processo de investigação desta pesquisa está pautado na abordagem qualitativa do tipo exploratória (GIL, 2008). O objetivo deste artigo é analisar a organização e o uso de Ambientes Virtuais de Aprendizagem em dois cursos de graduação presenciais, de duas instituições de ensino superior, que utilizam a modalidade a distância em até $20 \%$ do curso. Utilizam-se análise documental e dados coletados por meio da observação no Ambiente Virtual de Aprendizagem de duas instituições de ensino superior, sendo uma pública e outra privada. As fases da pesquisa estão descritas no quadro 1.

Quadro 1: Etapas da Pesquisa

\begin{tabular}{|c|c|}
\hline Etapa & Descrição \\
\hline 1- Estudo exploratório & $\begin{array}{l}\text { Estudo exploratório, documental e } \\
\text { empírico } \\
\text { Análise documental } \\
\text { Observação }\end{array}$ \\
\hline $\begin{array}{l}2 \text { - Sistematização e análise de } \\
\text { conteúdo }\end{array}$ & Categorização e sistematização \\
\hline
\end{tabular}

Fonte: elaborado pelos autores (2018)

\section{RESULTADOS}

O Ambiente Virtual de Aprendizagem (AVA) tem sido utilizado como sala virtual nas disciplinas de dois cursos da graduação presencial que ofertam até $20 \%$ de sua carga horária na modalidade a distância. Os cursos analisados são de áreas similares. O quadro 2 explicita as características encontradas nos documentos institucionais. 
Quadro 2: características dos cursos analisados

\begin{tabular}{|c|c|c|}
\hline & IES PÚBUICA - CURSO A & IES PRIVADA - CURSOB \\
\hline $\begin{array}{l}\text { Número de } \\
\text { estudantes }\end{array}$ & 250 estudantes & 95 estudantes \\
\hline Carga horária & $\begin{array}{l}3200 \text { horas / } 73 \text { DISCIPLINAS - } 44 \\
\text { semipresenciais }\end{array}$ & $\begin{array}{l}3344 \text { horas / } 54 \text { DISCIPLINAS } \\
\text { semipresenciais }\end{array}$ \\
\hline AVA & $\begin{array}{l}\text { Utiliza o AVA em todas as } \\
\text { disciplinas com atividades } \\
\text { avaliativas }\end{array}$ & $\begin{array}{l}\text { Utiliza o AVA em todas as disciplinas } \\
\text { com atividades avaliativas }\end{array}$ \\
\hline $\begin{array}{l}\text { Aulas } \\
\text { presenciais }\end{array}$ & Aulas presenciais diárias & Aulas presenciais diárias \\
\hline $\begin{array}{l}\text { Tecnologias } \\
\text { educacionais }\end{array}$ & $\begin{array}{l}\text { AVA, fórum, Computador, data } \\
\text { show, videoaulas, midias sociais, } \\
\text { quadroe giz, email, textos, slides }\end{array}$ & $\begin{array}{l}\text { AVA, computador, data show, } \\
\text { videoaulas, quadro e giz, textos, slides, } \\
\text { cd, celular, livro, papel e caneta }\end{array}$ \\
\hline
\end{tabular}

Fonte: elaborado pelos autores (2018)

Os resultados da pesquisa documental apontam o AVA como a principal tecnologia educacional utilizada no curso da IES privada. Indicam ainda que o AVA é utilizado para:

\begin{abstract}
publicação do plano de ensino, o envio de avisos instantâneos aos alunos, a publicação de materiais de aula e links de acesso a internet, a realização de avaliações e exercícios online, a realização de atividades em grupo, a realização de atividade síncronas com o chat, a realização de atividades assíncronas como o fórum, o blog $e$ construção conjunta de trabalhos via wiki, a publicação de notas, a publicação de vídeo-aulas, entre outros (PPC da IES PRIVADA, 2012, p. 181).
\end{abstract}

A IES desenvolveu o AVA com tecnologia própria e o implantou em 2013. É utilizado em todas as disciplinas do curso. Sua interface apresenta as seguintes ferramentas de apoio ao estudante: roteiro de estudo, avaliações, tutoria, estudantes, fórum, trabalhos, chat, rádio-web e avisos.

Na IES pública, o AVA utilizado é o Moodle. A plataforma disponibiliza ferramentas que podem ser utilizadas na interação e socialização dos discentes, tais como e-mail, fóruns de discussão e chats (discussão em tempo real), dentre outras.

\title{
5 DISCUSSÃO
}

A observação de três salas virtuais nas duas IES demonstra que o AVA é utilizado como repositório de materiais multimidiáticos e para realização de atividades. Na IES privada, - AVA é utilizado da mesma forma em todas as disciplinas. A criação, a seleção de conteúdos e a elaboração de atividades não são necessariamente realizadas pelo docente responsável pela disciplina. As atividades mais utilizadas são questionários, que 
possuem questões objetivas de múltipla escolha e apresentam feedback automático. Observaram-se cinco momentos de realização de questionário durante a realização da disciplina A. Além dos questionários, houve o envio de três atividades realizadas em grupo para fins de registro. Não houve atividades que utilizaram as ferramentas de fórum ou chat. $\mathrm{O}$ docente utilizou os avisos três vezes para enviar notícias sobre as atividades que deveriam ser postadas.

Na IES pública, cada docente personaliza sua sala virtual. Participaram da disciplina B 24 estudantes. As seis atividades programadas para substituir $20 \%$ da carga horária da disciplina $B$, utilizaram as ferramentas fórum e envio de arquivo. Mesmo com a utilização da ferramenta fórum (do tipo geral), não se observaram discussões ou interação entre os estudantes. As duas atividades propostas tinham como proposição um estudo de caso e, ao final, os estudantes deveriam responder a algumas questões. Percebeu-se que as participações dos estudantes tiveram como objetivo a resposta pontual de cada questão mecanicamente.

$\mathrm{Na}$ primeira atividade, 19 estudantes participaram. Somente as duas primeiras respostas tiveram algum comentário. A primeira postagem recebeu apenas um comentário, feito pelo docente que dizia: "Bom link" (Professor P9, IES pública 2017). A segunda postagem recebeu cinco comentários, além da postagem do estudante que abriu 0 tópico, duas delas feitas pelo docente com o teor de instigar a reflexão: "Ideias bem colocadas. E se o gerente de projeto no tiver todo o conhecimento técnico, mesmo assim ele poderia ser o gerente do projeto?" (Professor P9, IES pública 2017). Os outros comentários foram feitos por uma estudante e dois outros comentários pelo estudante autor da postagem. As outras 17 inserções não receberam comentários.

A segunda atividade teve 17 participações e 4 comentários. Os comentários foram feitos por quatro diferentes estudantes. Uma das postagens foi feita pelo docente, abrindo uma reflexão ao final do prazo da atividade: "Este exercício foi realizado em sala de aula no início da disciplina. De lá para cá a visão da equipe mudou? Se sim, o quê mudou?" (Professor P9, IES pública 2017). Dois estudantes interagiram com a questão inserida pelo docente. Dos 19 estudantes que participaram do primeiro fórum, 13 participaram do segundo e 3 que participaram do segundo fórum não participaram do primeiro.

Silva (2006 apud ROSTAS; ROSTAS, 2009, p. 138) explicita que "dentro de um ambiente online se valorizam a interação e a troca de informações entre professor e aluno, no lugar da reprodução passiva de conteúdos utilizando a oratória." Tal interação praticamente não ocorreu neste ambiente. A escolha da ferramenta fórum para desenvolver o estudo de caso deveria estar ligada aos objetivos pedagógicos, 
propiciando interação e diálogo com a participação docente, a fim de instigar a reflexão e a interatividade.

A disciplina $\mathrm{C}$ apresenta uma organização espacial diferente da sala da disciplina B. $O$ docente parece ter mais habilidade com a plataforma e explora diferentes ferramentas, tais como: envio de arquivo (3), questionário (3), wiki (3), laboratório de avaliação (1), fórum (3), glossário (1) e autoavaliação (2). Todas estas atividades substituem 9 horas $(20 \%)$ da carga horária total da disciplina. A sala possui 37 estudantes matriculados. Dos três fóruns propostos, apenas um era avaliativo. Os outros dois tinham objetivo de comunicação entre docente e estudantes. Silva (2006 apud ROSTAS; ROSTAS, 2009, p. 139) ressalta que o "ambiente virtual de aprendizagem, que representa a sala de aula online, é um conjunto de interfaces, ferramentas e estruturas decisivas para a construção da interatividade e da aprendizagem". As atividades que utilizaram a ferramenta fórum foram organizadas como um fórum geral. Cada tópico foi aberto pelo docente ou pelo monitor da disciplina e iniciava uma discussão simples.

O fórum 3 teve o objetivo de desenvolver uma atividade e de enviar notícias. Ao final de cada atividade, o professor e o monitor faziam uma inserção, tecendo uma costura textual e indicando referências complementares. Na atividade desenvolvida no fórum, 19 estudantes participaram. As 12 interações dos dois monitores sobre as postagens individuais tinham o objetivo de avaliar a postagem feita com base nos critério de avaliação ou de orientar quanto à realização correta da atividade. Durante o período de realização, o monitor fez uma postagem encorajando as postagens: "A participação de vocês é muito importante para uma aprendizagem efetiva. Para quem cumpriu o proposto já foi avaliado e dado feedback. Abaixo segue o texto usado de referência para esta atividade" (Monitor disciplina C, 2017).

Ao considerar os tipos de interações destacadas por Moore (1989), pode-se perceber que o Fórum 1 teve a participação de $79 \%$ dos estudantes matriculados (alunoconteúdo) e houve pouca interação aluno-aluno (12,5\%) e aluno-docente (12,5\%). fórum 2 teve $66 \%$ de participações dos estudantes (aluno-conteúdo), e também pouca interação aluno-aluno (16,6\%) e quase nenhuma interação docente (4\%). O fórum 3 teve a menor taxa de participação dos estudantes (51\%) (aluno-conteúdo), pouca interação entre os estudantes (10\%) e maior participação dos monitores da disciplina (32\%), porém sem retorno dos estudantes. 


\begin{tabular}{|l|l|l|l|l|l|}
\hline Atividade & Disciplina & $\begin{array}{l}\text { Estudantes } \\
\text { matriculados }\end{array}$ & Participações & $\begin{array}{l}\text { Comentários } \\
\text { dos estudantes }\end{array}$ & $\begin{array}{l}\text { Comentários } \\
\text { do docente/ } \\
\text { monitor }\end{array}$ \\
\hline Fórum 1 & $\mathrm{B}$ & 24 & 19 estudantes & 3 & 3 \\
\hline Fórum 2 & $\mathrm{B}$ & 24 & 16 estudantes & 4 & 1 \\
\hline Fórum 3 & $\mathrm{C}$ & 37 & 19 estudantes & 2 & 12 \\
\hline
\end{tabular}

Fonte: Elaborado pelos autores (2017)

Percebeu-se que mesmo o fórum 3 tendo os monitores participativos e oferecendo feedbacks na atividade, e ainda a atuação participante do docente na plataforma, os estudantes ainda interagiram pouco (entre eles e com os docentes/monitores), atendose a responder a proposta sinteticamente. Considerando a definição de Belloni (2003, p. 58) de interação como "ação recíproca entre dois ou mais atores onde ocorre intersubjetividade", a atividade não propiciou interação, visto que apenas dois estudantes fizeram comentários, porém complementando sua postagem sem a ação recíproca entre os sujeitos.

\section{CONSIDERAÇÕES}

Diante disso, constatou-se que o ambiente virtual de aprendizado é utilizado em todas as disciplinas de ambos os cursos, tendo como principal objetivo a disponibilização de materiais audiovisuais e a realização de avaliações.

Na IES privada, percebe-se que as avaliações realizadas no AVA são questionários com questões objetivas que possuem correção automática sem interação, enquanto as questões discursivas são corrigidas pelos docentes da disciplina. Ressalta-se ainda que as atividades não são necessariamente planejadas e escritas pelo docente da disciplina. As avaliações realizadas pelo AVA na IES pública são atividades diversificadas, planejadas, escritas e corrigidas pelo próprio docente, porém se observou que os recursos da plataforma são pouco utilizados por alguns docentes, limitando-se à utilização de fóruns e tarefas, tampouco promovendo a interação.

A interação dos estudantes com os mediadores e/ou com os colegas vai além da presença e mediação dos professores/monitores e do uso de recursos disponíveis na plataforma virtual. Não se observaram mediações reflexivas que propiciassem o diálogo entre os participantes. Portanto, os cursos possuem propostas distintas de utilização do AVA, havendo, entretanto, espaço para se avançar para que a utilização de ambas as plataformas atinja maior potencial de interação. Sugere-se que estudos futuros 
investiguem os fatores de interação no AVA.

\section{REFERÊNCIAS}

ALMEIDA, Maria Elizabeth Bianconcini de. Educação a Distância na Internet: abordagens e contribuições dos ambientes digitais de aprendizagem. Educação e Pesquisa, Pontifícia Universidade Católica de São Paulo, São Paulo, v. 29, n. 2, p. 327-340, jul./dez. 2003. Disponível em: . Acesso em: 29 abr. 2018.

BACICH, L.; TANZI NETO, A.; TREVISANI, F. M. (Org.). Ensino híbrido: personalização e tecnologia na educação. 1. ed. Porto Alegre: Penso, 2015.

BELLONI, M. L. Educação a distância. Campinas, SP: Autores Associados, 2003.

BRASIL. Ministério da Educação. Portaria no 1134, de 10 de Outubro de 2016. Regulamenta a oferta de carga horária a distância em disciplinas presenciais. Brasília, 2016. Disponível em: . Acesso em: 10 fev. 2017.

GIL, A. C. Métodos e técnicas de pesquisa social. 6. ed. São Paulo: Atlas, 2008.

HORN, M. B.; STAKER, H. Blended: Usando a inovação disruptiva para aprimorar a educação. Porto Alegre: Penso, 2015.

IES PRIVADA. Projeto Pedagógico de Curso. Curitiba, 2012.

KENSKI, V. Educação e tecnologias: o novo ritmo da informação. São Paulo: Papirus, 2012.

LAKATOS, E. M. Sociologia Geral. São Paulo: Atlas,1999.

MASETTO, M. T. (Org.). Inovação no Ensino Superior. 1. ed. São Paulo: Edições Loyola, 2012

MATTAR, J. Design educacional: educação a distância na prática. São Paulo: Artesanato Educacional, 2014.

MOORE, M. G. Editorial: Three types of interaction. American Journal of Distance Education, v. 3, n. 2, p. 1-6, 1989. 
MORAN, J. M. Mudando a educação com metodologias ativas. In: Convergências midiáticas, educação e cidadania: aproximações jovens. Vol. II, Coleção Mídias Contemporâneas. UEPG/PROEX, 2015. Disponível em: Acesso em: 7 jul. 2017.

ROSTAS, M. H. S. G.; ROSTAS, G. R. O ambiente virtual de aprendizagem (moodle) como ferramenta auxiliar no processo ensino-aprendizagem: uma questão de comunicação. In: SOTO, U.; MAYRINK, M. F.; GREGOLIN, I. (Org.). Linguagem, educação e virtualidade [online]. São Paulo: Editora UNESP; São Paulo: Cultura Acadêmica, 2009.

TORI, R. Educação sem distância. Artesanato Educacional: São Paulo, 2017. 